\title{
Embedded Health Librarianship: The Canadian Landscape $^{1}$
}

\author{
Liz Dennett, Trish Chatterley, Devon Greyson, and Soleil Surette
}

\begin{abstract}
Introduction: Previous research has identified various types of embedded librarianship - the clinical informationist, the academic liaison librarian, and the special librarian within a corporation. There is far less mention of librarians who are embedded in health research teams; however, the authors' personal experiences indicate these positions are not rare. The research-embedded health librarian (REHL) provides tailored, intensive information services to a health research team in which the REHL is integrated. This research study aims to describe the REHL workforce in Canada, noting how the characteristics of both the positions and the individuals holding them differ from those of health librarians in more traditional librarian roles. Methods: As Part I of a two-part mixed methods study, an electronic survey was distributed to Canadian health librarians. The survey gathered demographic data on all respondents and information on the work environments and experiences of self-identified REHL respondents. Descriptive data analysis was conducted, and statistical differences between REHLs and non-REHLs were calculated. Results: One hundred and ninety-one individuals completed the survey, with 39 (20\%) self-identifying as REHLs. The results indicated that REHLs tend to be both younger and newer to the profession than librarians in non-REHL positions. They are more likely to work for research institutes and nonprofit organizations, and they are less likely to work in hospital environments. They are also more likely to be hired on term-specific contracts than on a permanent basis. Discussion: More survey respondents identified themselves as REHLs than was anticipated, which may indicate that this a growing segment of the health librarian workforce. The high number of contract positions could be one explanation for why REHLs tend to be younger librarians or librarians who are newer to the profession, as they are just starting out in their careers. The predominance of contract positions is likely influenced by the high number of jobs in research institutes or nonprofit organizations where continuance of the positions is dependent on securing grant funding.
\end{abstract}

\section{Introduction}

As the amount of published information increases each year, many students, faculty, and professionals increasingly require highly tailored and in-depth information support services to carry out their work. The phrase "embedded librarianship" has become somewhat of a catch-all for service innovations that lead to more intensive information support for a client group, and in recent years, a significant amount of literature about this topic has been produced including two major surveys by the Special Library Association and the Medical Library Association [1, 2]. Literature on embedded librarianship tends to focus on three types of positions: academic librarians embedded into a course or department, business librarians embedded within units of larger companies or institutions, and clinical informationists embedded in health care settings. There is far less mention of librarians who are embedded in health research teams, (or in any other type of research team, for that matter). Research-embedded health librarian (REHL) positions share commonalities with the other types of embedded librarianship; however, without knowing more about the extent and nature of these positions, it is difficult to determine their importance and contribution to the embedded librarianship landscape. This paper presents the results of a national survey on REHLs in Canada, as part of a project to describe and define these positions.

Academic "embedded librarianship" typically involves liaison librarians providing intensive information support to target academic departments and (or) courses. This may take the form of physically moving out of the library and

\footnotetext{
Liz Dennett. ${ }^{2}$ John W. Scott Health Sciences Library, University of Alberta, Edmonton AB T6G 2R7 and Institute of Health Economics, Edmonton AB.

Trish Chatterley. John W. Scott Health Sciences Library, University of Alberta, Edmonton AB T6G 2R7.

Devon Greyson. School of Population and Public Health, University of British Columbia, 2206 East Mall, Vancouver, BC V6T 1Z3. Soleil Surette. Edmonton Public Library, 7 Sir Winston Churchill Square, Edmonton AB T5J 2 V4.

${ }^{1}$ This paper was peer-reviewed.

${ }^{2}$ Corresponding author. (E-mail: Liz.dennett@ualberta.ca)
} 
into the academic department they serve to be more readily available to faculty and students or becoming integrated into a face-to-face or online course throughout the semester [3-6]. Academic librarians who are embedded in departments sometimes become quite involved in providing research support for the faculty they serve [7, 8] but generally do not indicate that they feel part of a research team. An exception to this is certain Purdue librarians who become embedded in research projects rather than departments [9]. In the corporate world, librarians are also being relocated with their client groups and changing their focus from library-centric to customer-centric service $[1,10]$.

Within the health sciences, librarians have been integrated into clinical teams since the 1970s [11]. In 2000, Davidoff and Florance [12] introduced the concept of the clinical informationist. The informationist is embedded in a health care team and has clinical knowledge in addition to advanced information retrieval and analysis skills. Since its introduction, the informationist concept has been applied beyond clinical settings to include biomedical, public health, health policy, and education teams. The U.S. Medical Library Association uses the term Information Specialist in Context (ISIC) to apply to this more inclusive notion of medical informationists [2].

Research and commentary about the informationist or ISIC tends to dominate the discussion of embedded health librarianship, yet it is unclear how many informationist positions exist. Rankin et al. [13] systematically reviewed the literature on the informationist specialty, identifying case reports from seven programs that met all four of their criteria for an informationist program. These attributes are (i) formal training in information science and a domainspecific area (e.g., pharmacy or medicine); (ii) in-depth understanding of work culture (e.g., research methods, clinical processes); (iii) in-context work as a team member or expert consultant; and (iv) critical appraisal and literature synthesis or data analysis skills. A further eight programs that met only some (i.e., one to three) of the defining attributes were also identified. So at a glance there appears to be as many programs that do not quite fit the informationist model as those that do. While the informationist or ISIC is an interesting development in health librarianship and may become more common as formal education pathways are created, health librarians are currently being employed in other successful embedded models that are not as well described in the literature.

To date, there is little published research on health librarians who are embedded within research teams. Shumaker's 2009 "Models of Embedded Librarianship" report for the Special Libraries Association identifies that research embedded librarians exist but are "less prominent in the literature" [1]. Since that report, there have been several articles published that provide case studies of research embedded librarians [9, 14], but the extent and nature of these positions in the health sciences remain mostly undocumented. The health sciences are perhaps a special case of research embedded librarians because of the importance of systematic reviewing as a form of research in these disciplines and the integral contribution of the librarian to this methodology [15]. We believe this clearly defined role for the librarian may make it easier for them to fully embed in health research teams than in other disciplines. We undertook this research to better understand the nature of the REHL work and workforce in Canada and the professional and educational needs of current and future REHLs. This paper presents comparisons between the REHL workforce and librarians employed in more traditional roles in Canada. A second paper reporting qualitative data from Part II of the survey and the focus groups conducted will paint a picture of the typical REHL role, and discuss the professional needs of this workforce. That paper will be published in a forthcoming special issue of Journal of the Medical Library Association (Vol. 101, Issue 4, October 2013).

\section{Objectives}

This research study aimed to document the phenomenon of REHLs in Canada and to describe: (i) where Canadian REHL jobs are located and what the conditions of employment are for these positions; (ii) the demographics, educational background and career histories of REHLs; and (iii) whether and how REHLs differ from other health librarians in Canada.

Based on the authors' personal experiences as REHLs and from our observations of other REHLs, we hypothesized that the REHL workforce in Canada would tend to be younger, newer librarians than the non-REHLs, that REHLs would have more part-time and term-limited contract work, would have lower salaries, and that they would be less likely to be affiliated with professional health library associations.

\section{Methods}

We conducted a two-part online survey. The first part was open to all Canadian health librarians, and respondents who met our REHL inclusion criteria were invited to complete the second REHL-specific section. This paper reports on the results of Part I of the survey. The study was approved by the ethical review boards of the University of Alberta and University of British Columbia.

The survey was drafted in English, translated into French to ensure accessibility across Canada, and piloted on a group of health librarians who had formerly worked as REHLs. The survey was administered via the bilingual Canadian FluidSurveys online software over a period of 4 weeks in March and April 2011. Invitations to participate in the survey and two reminder emails were sent out via CANMEDLIB (the primary listserv for Canadian Health Librarians) and various smaller Canadian listservs of interest to health librarians. All Canadian health librarians and information specialists were invited to participate in the survey, which included questions about educational background, career history, employment conditions, and some demographic information. The complete survey (in English) is available in Appendix A.

For the last question of Part I of the survey, participants were presented with the research team's definition of an REHL and were asked if they met the listed criteria. The definition was presented within the survey as follows: 
A Research-Embedded Health Librarian:

Participates in a research team(s) rather than focusing on traditional library management and services

AND

Provides tailored, intensive information services to a health research team with which $\mathrm{s} / \mathrm{he}$ is integrated

The following are not, for the purposes of this study, considered to be Research-Embedded Health Librarians: Academic liaison librarians, Clinical informationists, General hospital librarians, Librarians with library managementfocused jobs, Self-employed information consultants.

Research-Embedded Health Librarians may hold other nonembedded positions concurrently with a research-embedded job.

The respondents who identified themselves as a REHL were asked to participate in Part II of the survey, which focused on descriptive questions regarding the nature of their jobs and responsibilities. These respondents were considered to be our REHL population, and their survey results from Part I were compared against those from the non-REHL respondents and reported in this paper. The results of the REHL-only survey module have been analyzed in conjunction with qualitative data from subsequent REHL focus groups, and reported in a second paper that is currently in press.

\section{Statistical analysis}

Data from the survey was coded and analyzed with Predictive Analysis Software Statistics for Mac (PASW version 18.0, IBM SPSS, Somers, N.Y.). To test our hypotheses and to determine if other demographics (e.g., age) or job-related variables (e.g., type of employing organization) differ significantly between REHLs and nonREHLs, we used Pearson's $\chi^{2}$ test with 1 degree of freedom and we reported the associated $p$ values for this statistic. As Pearson's $\chi^{2}$ test is inappropriate if the expected frequency of any cell in a $2 \times 2$ table is less than 5, Fisher's exact test was used in those cases [16] and the associated $p$ values (which are more conservative) were provided instead (indicated later in the paper with $*$ ); $p$ values of less than 0.05 were considered statistically significant.

\section{Results}

One hundred and ninety-one individuals completed the survey. Thirty-nine $(20.4 \%)$ identified themselves as REHLs. The geographical distribution of health librarian positions in Canada is shown in Table 1. There were no survey respondents from Prince Edward Island or any of the territories. The percentage of REHL positions in any given province is generally similar to the percentage of non-REHL positions in that same province. Alberta is the exception. Albertan non-REHL respondents made up 11\% of total non-REHLs in Canada, while Albertan REHL respondents made up $21 \%$ of the Canadian REHL total.

As Figure 1 demonstrates, among survey respondents, REHLs tended to be younger than non-REHLs. Fewer
Table 1. Geographic distribution of health librarian positions in Canada.

\begin{tabular}{lccc}
\hline Province & $\begin{array}{l}\text { REHL } \\
(n=39)\end{array}$ & $\begin{array}{l}\text { non-REHL } \\
(n=152)\end{array}$ & $\begin{array}{l}\text { Combined } \\
(n=191)\end{array}$ \\
\hline ON & $13(33.3 \%)$ & $53(34.9 \%)$ & $66(34.6 \%)$ \\
QC & $8(20.5 \%)$ & $28(18.4 \%)$ & $36(18.8 \%)$ \\
BC & $7(17.9 \%)$ & $27(17.8 \%)$ & $34(17.8 \%)$ \\
AB & $8(20.5 \%)$ & $16(10.5 \%)$ & $24(12.6 \%)$ \\
MB & $1(2.6 \%)$ & $8(5.3 \%)$ & $9(4.7 \%)$ \\
NS & $2(5.1 \%)$ & $7(4.6 \%)$ & $9(4.7 \%)$ \\
SK & 0.0 & $5(3.3 \%)$ & $5(2.6 \%)$ \\
NB & 0.0 & $5(3.3 \%)$ & $5(2.6 \%)$ \\
NL & 0.0 & $2(1.3 \%)$ & $2(1.0 \%)$ \\
\hline
\end{tabular}

Fig. 1. REHL and non-REHL birth year distribution.

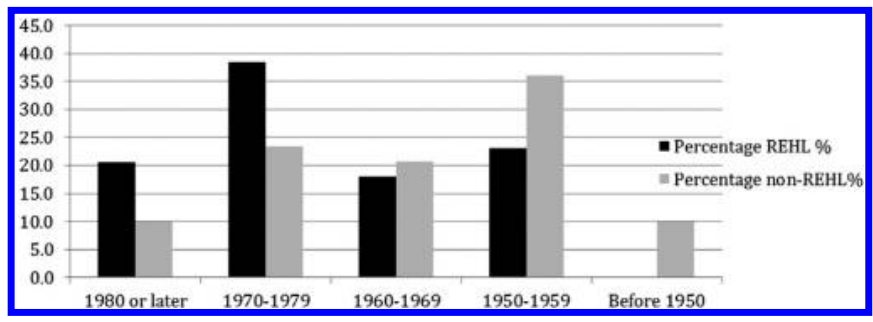

REHL respondents were born prior to 1960 (23\% compared with $46 \%$ of non-REHLs $(p=0.009)$ ). Conversely, almost $60 \%$ of REHLs were born after 1970 compared with just $33 \%$ of non-REHLs $(p=0.003)$.

As demonstrated in Figure 2, 71.8\% of REHLs obtained their MLIS or equivalent degree in 2000 or later compared with just $38.4 \%$ of non-REHLs ( $p=0.0002$ ). Only $12.9 \%$ of REHLs had obtained their MLIS prior to 1990 compared with $34.3 \%$ of non-REHLs $(p=0.009)$. The trends therefore indicate that REHLs tend to be both younger and newer to the profession than librarians in non-REHL positions. If the results are broken down even further for more recent graduates, $46.2 \%$ of REHLs received their MLIS between 2005 and 2010 compared with $24.7 \%$ of non-REHL $(p=0.009)$. Thus, almost half the librarians in REHL positions at the time of the survey had graduated within the previous five years.

In addition to being more recent graduates, REHLs were also newer to health librarianship specifically. REHLs were more likely to have been working in health librarianship for 5 years or less $(53.8 \%$ compared with $28.9 \%$ $(p=0.003))$ and were less likely to have been working in health librarianship for more than 20 years $(5.1 \%$ compared with $30.9 \%(p=0.001))$. REHLs were newer to their current positions as well; they were more likely to have been employed in their current position for five years or less $(70.2 \%$ compared with $46.3 \%(0.009))$ and less likely to have been in the same job for more than 10 years $(13.5 \%$ compared with $34.4 \%(p=0.01))$.

Figure 3 displays the employing organization of REHLs as compared with non-REHLs. Respondents could select more than one category, so percentages do not add up to $100 \%$. As can be seen, REHLs were more likely to 
Fig. 2. REHL and non-REHL year MLIS received.

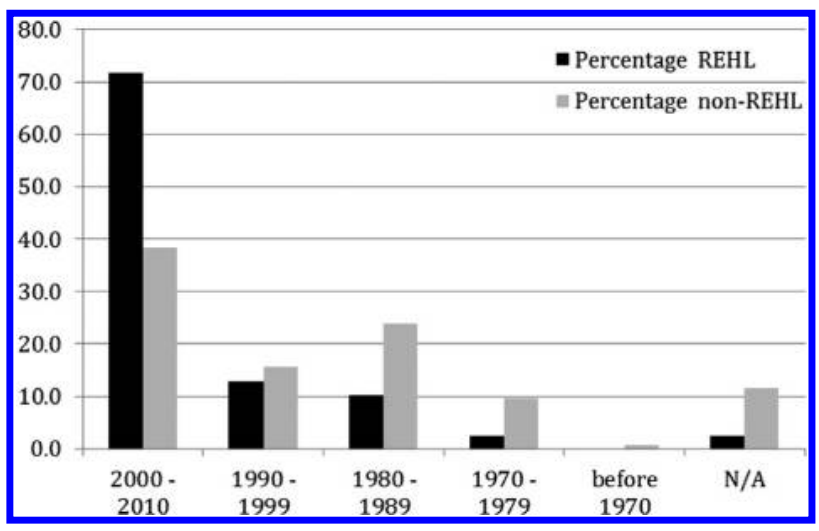

Fig. 3. REHL and non-REHL employer type.

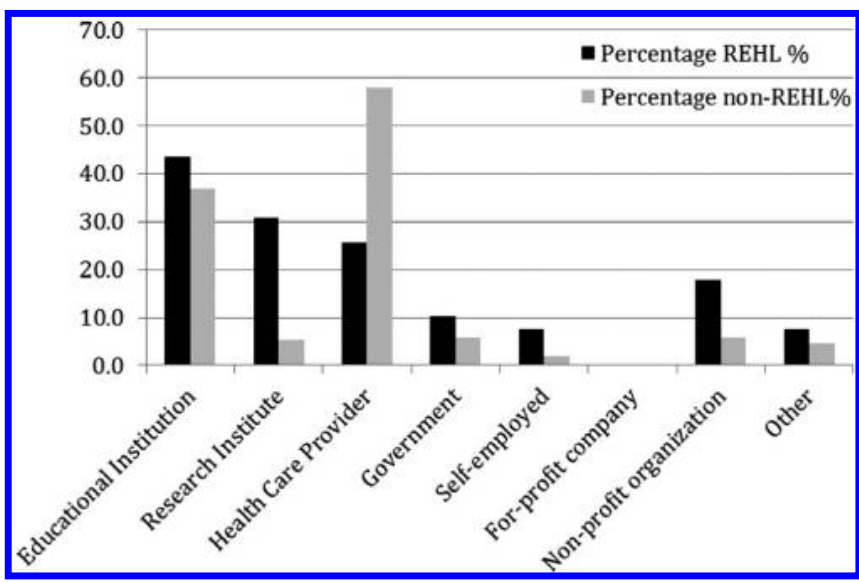

Fig. 4. REHL and non-REHL type of contract.

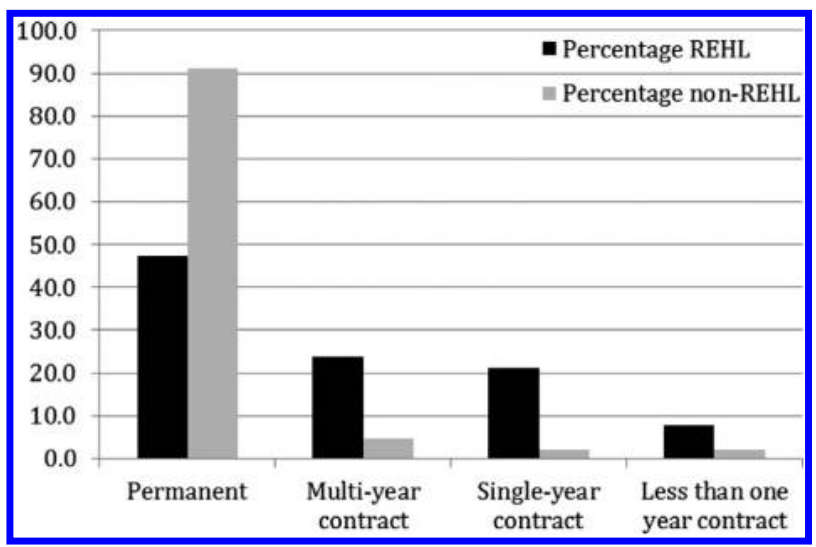

work for research institutes $(30.8 \%$ compared with $5.3 \%$ $\left.\left(p=0.000^{*}\right)\right)$ and nonprofit organizations $(17.9 \%$ compared with $\left.5.9 \%\left(p=0.02^{*}\right)\right)$ and less likely to work for hospitals or other health care providing institutions $(25.6 \%$ compared with 57.9\% $(p=0.000))$. There was no statistically significant difference in the proportions of REHLs and non-REHLs $(43.6 \%-36.8 \%(p=0.44))$ working at educational institutions.
The majority of health librarians in both REHL and non-REHL positions were employed full-time, with similar proportions in each group working in one or multiple parttime positions. Most health librarians work between 35 and 40 hours per week, with a higher proportion of REHLs $(20.5 \%$ compared with $9.2 \%(p=0.09))$ working more than 41 hours per week (this difference is not statistically significant). However, the contractual nature of positions is considerably different. As exhibited by Figure 4, REHLs were much less likely to hold permanent positions $(47.4 \%$ compared with $91.2 \%(p=0.000))$ and more likely to have multiyear $(23.7 \%$ compared with $4.8 \%$ $\left.\left(p=0.001^{*}\right)\right)$ or single-year contracts $(21.1 \%$ compared with $\left.2.0 \%\left(p=0.000^{*}\right)\right)$.

Although there are differences in the ratios of contracts held between the two groups, there were no statistically significant differences in annual salary. However, in the salary ranges above $\$ 70,000$ per year, non-REHLs were found in consistently slightly higher proportions than REHLs.

The majority (over 60\%) of both REHLs and nonREHLs were members of CHLA/ABSC. In both groups, the majority (over 55\%) were also members of local CHLA/ ABSC chapters. Approximately $15.4 \%$ of REHLs and $6.0 \%$ of non-REHLs did not belong to any professional association. While there were no statistically significant differences between the two groups, non-REHLs had slightly higher proportions of individuals who were organization members in nearly every category. The two exceptions where REHLs were more strongly represented are the Canadian Library Association and the Special Library Association.

\section{Discussion}

The proportion of survey respondents who selfidentified as REHLs was higher than anticipated. This could be a result of response bias, with REHLs potentially being more interested in the outcome and therefore more likely to complete the survey than others. Alberta had a higher proportion of REHL to non-REHL positions than any other province, with $1 / 5$ of the REHL positions compared with just $1 / 10$ of the non-REHL workforce in Canada. While this may accurately represent the demographics of the Alberta health library workforce, response bias is a possibility given that the majority of the study team members are current or former REHLs in Alberta.

Our hypotheses that REHL respondents would tend to be younger and newer librarians, and that they hold more term-limited contracts, appear to be supported. REHLs were almost twice as likely as non-REHLs to have been born after 1970. REHLs were also almost twice as likely to have received their MLIS after 2005, and approximately only $1 / 3$ as likely to have obtained their MLIS prior to 1990. Significantly more REHLs reported having held their current positions for fewer than 5 years compared with non-REHLs. One possible explanation for this difference is that many REHL positions may have been created more recently than traditional health library positions. Another possibility could be that there is more turnover in these positions. Turnover may result from the high predominance of contract positions reported by 
REHLs or possibly from the lack of career advancement opportunities, particularly in organizations with only one librarian or information specialist.

The issue of staff retention has potential implications for professional library associations. Less experienced librarians may not necessarily have the full complement of skills necessary to step right into these roles and will therefore need training to develop those skills. As many of these individuals are the solo librarian in a particular institution, there may not be other information specialists on staff who can provide that training. Therefore, associations should strive to develop continuing education opportunities or other support mechanisms for this seemingly growing subgroup of health librarians. Some of the onus for training could be achieved through additional course offerings in graduate level library or information science programs. The availability of practicum or co-op opportunities for students with institutions that hire REHLs could be another means of building capacity. Library schools could also raise awareness of REHL-type positions among graduates by inviting REHLs to speak to their students as guest speakers or at career days.

The high number of contract positions may relate to the organization of employment. REHLs are more likely to work in research institutes or for nonprofit organizations, which tend to rely heavily on grant funding, and are much less likely to work in health care institutions. Because grant funding cannot be guaranteed from year to year, some organizations may not be financially or contractually able to offer permanent work.

Roughly $44 \%$ of REHLs are affiliated with educational institutions in some capacity. This has a number of implications for academic libraries and librarians. While REHLs working with research groups are not always affiliated with the central library system, all health librarians at a single institution can benefit from networking and developing skills together via journal clubs, discussion groups, or offering cross-training opportunities. Libraries can potentially offer database training, access to library software, and mentoring, whereas REHLs bring deep knowledge of specific subject areas, expertise in research methods, and strong relationships with academic researchers. REHLs in an academic milieu should not be seen as competition for liaison librarians but rather as partners offering complementary services in support of the research mandate of the school, thereby freeing academic librarians to build strong collections, support teaching, and provide effective service to their student populations. Similar scenarios could be developed in hospital environments, where $1 / 4$ of REHLs are employed. Librarians employed by the hospital library system should be aware of colleagues in research-embedded roles, and they should work together to network, collaborate, and provide crosstraining opportunities.

Given the higher proportion of REHLs who were new to the profession in general and to health sciences librarianship in particular, one might suspect that they would earn less than those in non-REHL positions who have had longer careers and stayed in their current positions for longer periods. This hypothesis is not substantiated by the evidence, though there does appear to be a slightly higher proportion of non-REHLs who are on the higher end of the pay scale.

Although non-REHLs reported belonging to professional organizations in slightly higher proportions and REHLs were more likely to not belong to any professional groups, such differences were not statistically significant. The small differences observed could perhaps relate to differences in the nature of the contracts, as contract positions are less likely to come with other benefits such as professional allowances that would cover the costs of membership. Impression of relevance could also be a factor, with REHLs seeing membership as being somewhat less pertinent to their work.

The major limitation of this study is our inability to determine a response rate because of the lack of a reliable count of practicing health librarians in Canada. Therefore, while our response numbers and general demographics are in line with other major surveys of Canadian health librarians [17], it is not possible to state with certainty the extent to which these results are generalizable to the entire national population.

\section{Conclusion}

The results of this survey demonstrate that REHLs make up a small but significant proportion of health librarian positions in Canada. The librarians in these roles tend to be younger, have more recent MLIS degrees, and are more likely to work in term-limited contracts than the non-REHL respondents. They do not, however, have significantly lower salaries and were not statistically less likely to be members of professional library organizations.

This paper is the first step in a project to describe and define REHLs in Canada. Further qualitative research is underway to investigate the experiences, contributions, and unique needs of REHLs.

\section{Acknowledgements}

The authors would like to thank CHLA/ABSC for providing monetary support through the Chapter Initiatives Fund and the Northern Alberta Health Libraries Association (NAHLA) and the Health Libraries Association of British Columbia for supporting this project. Thanks also to NAHLA for managing the grant money. Thanks to Maria Ospina, Research Associate at the Institute of Health Economics, for her expertise and assistance with the statistical analysis.

\section{References}

1. Shumaker D, Talley M, Miervaldis W. Models of Embedded Librarianship: Final Report. Special Libraries Association; 2009. Available from: http://embeddedlibrarian.com/2013/04/ 13/models-of-embedded-librarianship-final-report/. [Accessed 28 May 2013.]

2. Giuse NB, Sathe NA, Jerome R. Envisioning the Information Specialist in Context (ISIC): A multi-center study to articulate roles and training models. Eskind Biomedical Library and Medical Library Association; 2006. Available from: 
http://cec.mlanet.org/2008-may/isic_final_report_feb06.pdf. [Accessed 28 May 2013.]

3. Shumaker D. Embedded Librarians in Higher Education. The Embedded Librarian: Innovative Strategies for Taking Knowledge Where it's Needed Medford, NJ: Information Today, Inc.; 2012. p. 43-67.

4. Drewes K, Hoffman N. Academic Embedded Librarianship: An Introduction. Public Services Quarterly. 2010;6(2-3):7582. doi: 10.1080/15228959.2010.498773.

5. Kesselman MA, Watstein SB. Creating Opportunities: Embedded Librarians. J Libr Admin. 2009;49(4):383-400. doi: 10.1080/01930820902832538.

6. Schulte SJ. Embedded Academic Librarianship: A Review of the Literature. EBLIP. 2012;7(4):122-138.

7. Freiburger G, Kramer S. Embedded librarians: one library's model for decentralized service. J Med Libr Assoc. 2009; 97(2):139. doi: 10.3163/1536-5050.97.2.013.

8. Bartnik L. The Embedded Academic Librarian: The Subject Specialist Moves into the Discipline College. Kentucky Libr. 2007;71(3):4-9.

9. Carlson J, Kneale R. Embedded Librarianship in the Research Context: Navigating New Waters. Coll Res Libr News. 2011;72(3):167-170.

10. Shumaker D. Embedded librarians in corporations, nonprofits, and government. The Embedded Librarian: Innovative Strategies for Taking Knowledge Where it's Needed Medford, NJ: Information Today, Inc.; 2012. p. 93-106.
11. Algermissen V. Biomedical librarians in a patient care setting at the University of Missouri-Kansas City School of Medicine. Bull Med Libr Assoc. 1974;62(4):354-358.

12. Davidoff F, Florance V. The informationist: a new health profession? Ann Intern Med. 2000;132(12):996. doi: 10.7326/ 0003-4819-132-12-200006200-00012.

13. Rankin JA, Grefsheim SF, Canto CC. The emerging informationist specialty: a systematic review of the literature. J Med Libr Assoc. 2008;96(3):194-206. doi: 10.3163/15365050.96.3.005.

14. Robinson-Garcia N, Torres-Salinas D. Librarians "Embedded" in Research. CILIP UPDATE with gazette. 2011:44-45.

15. Dudden RF, Protzko SL. The systematic review team: contributions of the health sciences librarian. Med Ref Serv Q. 2011;30(3):301-315. doi: 10.1080/02763869.2011. 590425 .

16. Lang TA, Secic M. How to report statistics in medicine: annotated guidelines for authors, editors, and reviewers. 2nd ed. Philadelphia: American College of Physicians; 2006.

17. Dingwall O, Dorgan M, Raworth R, Ticoll M. Taking the pulse of Canadian health information professionals: Canadian Health Libraries Association/Association des bibliothèques de la santé du Canada (CHLA/ABSC) 2010 survey. $J$ Can Health Libr Assoc. 2011;32(1):11-15.

\title{
Appendix A: Questions from Part 1 of the Survey
}

\author{
1. What is the highest library/information degree you have? \\ - Bachelor's \\ - Master's \\ - Doctorate \\ $\circ$ Other, please specify:
}

2. What is the highest nonlibrary/information degree you have?

$\circ$ Bachelor's

- Master's

- Doctorate

$\circ$ Other, please specify:

3. If you have a MLS/MIS/MLIS, when did you receive it?
- 2005 or later
- 2000-2004
- 1990-1999
- 1980-1989
- 1970-1979
- Before 1970
$\circ$ N/A

4. How many years, in total, have you worked in health librarianship?

$\circ$ Less than 2

- $2-5$

- $6-10$

○ 11-20

- 21-30

- More than 30 years 
5. For what type(s) of organization do you currently work? (Please check all that apply)

- University, College, or other educational institution

- Research institute

Hospital or health care provider

- Government

- Self-employed or employed by consulting firm

For-profit company or industry

- Nonprofit organization

Other, please specify:

6. How many hours a week do you work on average? If you have more than one position, please indicate the total from all positions.

- Less than 10

- 10-19

- 20-29

- 30-34

○ 35-40

- 41-50

- More than 50

7. Are you employed?

$\circ$ Full-time

- In a single part-time position

- In multiple part-time positions

- Other, please specify:

8. How long have you been employed in your current position? If you work multiple jobs, please answer for your primary health sciences position.

- Less than one year

1-2 years

- 3-5 years

- 6-10 years

- More than 10 years

9. Please describe the nature of your health sciences position. If you hold more than one health sciences position, please respond for your primary position.

- Permanent

- Multiyear contract

- Single-year contract

- Less than one year contract

10. What is your current annual salary before taxes and other in CDN \$? If you have more than one position, please indicate the total from all positions.

- Less than $\$ 30,000$

- \$30,000-\$39,999

- \$40,000-\$49,999

- \$50,000-\$59,999

- \$60,000-\$69,999

- \$70,000-\$79,999

- \$80,000-\$89,999

- $\$ 90,000-\$ 99,999$

- $\$ 100,000$ or more

11. Are you a member of a union or faculty association? (Please check all that apply.)

- Union

- Faculty association

- Other staff association

- No, I am not a member of an association/union 
12. To which professional associations do you currently belong? (Please check all that apply.)

- Canadian Health Libraries Association (CHLA/ABSC)

- Local CHLA/ABSC chapter or affiliate

- Medical Library Association (MLA)

- Canadian Library Association (CLA)

- Provincial or local general libraries association

- Special Library Association (SLA)

- Provincial or local special libraries association (nonhealth)

- Other health-related professional association (e.g., CMA, CNA, CAHSPR, HTAi) Please specify:

- I am not currently a member of a professional association

13. When were you born?
1980 or later
1970-1979
1960-1969
1950-1959
- Before 1950

14. Do you consider yourself to be part of a visible minority group?

$\circ$ Yes

$\circ$ No

15. Where do you currently work?

$\circ \mathrm{BC}$

$\circ \mathrm{AB}$

$\circ$ SK

$\circ \mathrm{MB}$

$\circ \mathrm{YT} / \mathrm{NWT} / \mathrm{NU}$

$\circ \mathrm{ON}$

$\circ \mathrm{QC}$

$\circ \mathrm{NB}$

$\circ \mathrm{NS}$

$\circ$ PEI

$\circ \mathrm{NL}$

$\circ$ Other, please specify:

Please read the definition below and then answer question 16

A Research-Embedded Health Librarian: Participates in a research team(s) rather than focusing on traditional library management and services AND provides tailored, intensive information services to a health research team with which s/he is integrated

The following are not, for the purposes of this study, considered to be Research-Embedded Health Librarians:

- Academic liaison librarians

- Clinical informationists

- General hospital librarians

- Librarians with library management -focused jobs

- Self-employed information consultants.

Research-Embedded Health Librarians may hold other nonembedded positions concurrently with a research-embedded job.

16. According to the definition above, do you consider yourself to be a Research-Embedded Health Librarian IN A JOB YOU CURRENTLY HOLD?

$\circ$ Yes

$\circ$ No 